\title{
Pandemi Koşullarında Otel Seçimiyle İlgili TOPSIS Tabanlı Bir Karar Verme Yaklaşımı
}

\author{
Sezin Güleryüz ${ }^{1 *}$, Abdullah Uluçay², İrfan Mert Yavuz ${ }^{3}$ \\ 1* Bartın Üniversitesi, İktisadi ve İdari Bilimler Fakültesi, Yönetim Bilişim Sistemleri Bölümü, Bartın, Türkiye, (ORCID: 0000-0002-9858-7115), \\ sezinguleryuz@gmail.com \\ 2 Bartın Üniversitesi, İktisadi ve İdari Bilimler Fakültesi, Yönetim Bilişim Sistemleri Bölümü, Bartın, Türkiye, (ORCID: 0000-0002-5493-2618), \\ abdullah.ulucay97@gmail.com \\ ${ }^{3}$ Bartın Üniversitesi, İktisadi ve İdari Bilimler Fakültesi, Yönetim Bilişim Sistemleri Bölümü, Bartın, Türkiye (ORCID: 0000-0002-1078-3892), \\ mymertyvz@gmail.com
}

(İlk Geliş Tarihi 15 Ekim 2021 ve Kabul Tarihi 6 Aralık 2021)

(DOI: 10.31590/ejosat.1010387)

ATIF/REFERENCE: Güleryüz, S., Uluçay, A. \& Yavuz, İ. M. (2021). Pandemi Koşullarında Otel Seçimiyle İlgili TOPSIS Tabanlı Bir Karar Verme Yaklaşımı. Avrupa Bilim ve Teknoloji Dergisi, (31), 951-956.

\section{$\ddot{O} z$}

Covid-19'un küresel ölçekte turizm sektörünü etkileyerek özellikle otel endüstrisi üzerinde büyük kayıplara neden olduğu yapılan çalışmalarca tespit edilmiştir. Ülkelerin sosyal ve ekonomik yapısını etkileyen Covid-19, daha önce turizm sektörü için benzeri görülmemiş bir durum olarak nitelendirilmiştir. Sosyal mesafe, ev karantinası, seyahat kısıtlamaları, sınırların kapatılması gibi çeşitli önlemler turizm ve konaklama tesislerinin faaliyetlerini durma noktasına getirmekte ve bazı tesislerin geçici olarak kapatılmasına neden olabilmektedir. Günümüz pandemi koşullarında müşteriler kalacakları oteli seçerken pandemi öncesi durumdan farklı bir yaklaşım sergileme eğilimindedirler. Pandemi koşullarına uygunluk, hijyen, covid-19'a karşı alınan önlemler, müşterilerin konaklama tercihlerini etkileyerek otel seçim süreçlerini etkilemektedir. Bu karar sürecinde, Çok Kriterli Karar Verme (ÇKKV) tekniklerinden TOPSIS (Technique for Order Preference by Similarity to Ideal Solutions) yöntemi kullanılarak pandemi şartlarında Türkiye turizm bölgelerindeki 7 büyük otelin aldığı önlemler incelenerek sonuçlar analiz edilmiş ve en güvenilir otel seçilmiştir. Çalışmanın özgünlüğü, literatürde sıklıkla kullanılan TOPSIS yönteminin, pandemide otel seçimi problemine yönelik gerçek bir vaka çalışmasında ilk kez uygulanmasından kaynaklanmaktadır.

Anahtar Kelimeler: Covid-19, Çok Kriterli Karar Verme, Topsis, Otel Seçimi

\section{A TOPSIS-Based Decision Making Approach for Hotel Selection in Pandemic Conditions}

\begin{abstract}
It has been determined by studies that Covid-19 affects the tourism sector on a global scale and causes great losses especially on the hotel industry. This pandemic, which affects the social and economic structure of the countries, has previously been described as an unprecedented situation for the tourism industry.Various precautions such as social distance, home quarantine, travel restrictions, closure of borders bring tourism and accommodation facilities activities to a standstill and may cause some facilities to be temporarily closed. In today's pandemic conditions, customers tend to take a different approach than the pre-pandemic situation when choosing a hotel to stay. Compliance with pandemic conditions, hygiene, measures taken against covid-19 affect customers' accommodation choices and affect hotel selection processes. In this decision process, using TOPSIS (Technique for Order Preference by Similarity to Ideal Solutions) method, which is one of the Multi-Criteria Decision Making (MCDM) techniques, the measures taken by 7 big hotels in Turkey's tourism regions were examined under pandemic conditions, and the results were analyzed and the most reliable hotel was selected. The originality of the study stems from the fact that TOPSIS technique, which is frequently used in the literature, was applied for the first time in a real case study for the hotel selection in pandemic conditions.
\end{abstract}

Keywords: Covid-19, Multi Criteria Decision Making, Topsis, Hotel Selection

*Sorumlu Yazar: Sezin Güleryüz, e-mail sezinguleryuz@gmail.com 


\section{Giriş}

Dünya genelinde Covid-19 salgını başladıktan sonra insanların yaşam şekilleri ve alışkanlıkları değişim göstermiştir. $\mathrm{Bu}$ değişimden turizm sektörü ve tatil alışkanlıkları da büyük ölçüde etkilenmiştir. Turizm sektörü için çok büyük bir kriz olan bu salgında insanların gidecekleri otellerin aldıkları önlemler büyük ölçüde önem kazanmıştır.

Değişen turizm şartlarında insanların yer seçimi, otel seçimi, otel uygunluğu ve ulaşım kısıtlaması her bakımdan önem kazanmıştır. Otellerin belirli kriterlere uyarak aldığı güvenli turizm sertifikası, planlama sürecinde insanların pandemi koşullarında otel seçimlerindeki en önemli kıstastır. Otellerin resmi web sitesinde bulunan bu sertifika ve sitedeki pandemi genelgesi insanlarla paylaşılarak otel güvenilirliğini sağlamak amaçlanmıştır. Otel seçimindeki karar verme, otellerin resmi web sitesindeki pandemi önlemleri insanlar için önem arz etmektedir. Pandemi koşullarında yapılan değerlendirmenin önem derecesi hijyen, dezenfekte işlemi, yeme-içme, toplu alan kullanımı ve genel değerlendirme öne çıkmaktadır.

Otel seçimi kavramını daha iyi değerlendirebilmek için niteliksel ve niceliksel tüm faktörleri ele almak gerekir. $\mathrm{Bu}$ yüzden tanımlanan kriterler doğrultusunda en uygun otel seçimi, çok kriterli karar verme (ÇKKV) problemi olarak ele alınabilir. $\mathrm{Bu}$ çalışmada, Covid-19 şartlarında en ideal otel seçimini literatürde sıklıkla kullanılan ÇKKV tekniklerinden Technique for Order Preference to Similarity to Ideal Solution (TOPSIS) (Hwang ve Yoon, 1981) kullanılarak, otellerin ideal sıralamas1 yapılmış ve uygunlukları belirlenerek sonuç sıralaması elde edilmiştir.

$\mathrm{Bu}$ çalışma kapsamında ilk aşamada, yapılan literatür taraması ve uzman görüşleri ile seçim kriterleri belirlenmiş ve değerlendirme modeli geliştirilmiştir. Çalışmanın ikinci aşamasında otel seçimi problemi için ÇKKV metodları incelenmiş, ideal ve anti ideal çözümde anlık değerlendirme olanağı sağlayan ve kolay programlanabilir sayısal sürece sahip olması gibi birçok avantajı bulunan TOPSIS seçilerek, Türkiye turizm beldelerinden Antalya bölgesinde bulunan oteller baz alınılarak 7 otel değerlendirilmeye alınmıştır. $\mathrm{Bu}$ otellerin pandemi koşullarına göre tercih edilme olanakları göz önünde bulundurularak sıralama yapılmıştır. Çalışmanın uygulama aşamasında Trivago ve Etstur gibi çevrimiçi seyahat sitelerinde yapılan müşteri yorumlarından faydalanılarak otel güvenilirliği, müşteri bakış açısıyla değerlendirilmiştir.

Çalışmanın literatüre katkısı, pandemi koşullarını dikkate alarak otel seçim problemi için TOPSIS metodu ilk kez gerçek bir vaka çalışmasıyla uygulanması ve benzer durumlarda olan karar vericilere rehberlik etmesi şeklinde özetlenebilir.

Makale aşağıdaki şekilde düzenlenmiştir: otel seçimi ile ilgili oluşturulan kriterler ve literatür taraması ikinci bölümde özetlenmiştir. İlaveten yine ikinci bölümde otel seçiminde kullanılan ÇKKV yöntemleri ele alınmıştır ve pandemi ile ilgili olan çalışmalar özetlenmiştir. Üçüncü bölümde kullanılan metodoloji adımlar yardımıyla sunulmuştur. Son bölümde uygulama adımlarının çıkarımları ve sonuçlar verilmiştir.

\section{Literatür Taraması}

\subsection{Otel Seçimi ve Önerilen Değerlendirme Kriterleri}

İncelenen otel seçimi ile ilgili yazın, Trivago ve Etstur gibi çevrimiçi seyahat siteleri ve uzmanların sundukları görüşler öncülüğ̈̈nde 7 ana kriter belirlenmiştir.

Hijyen ve temizlik: Hijyen, sağlığın korunması ve hastalıkların yayılmasının önlenmesine yardımcı olan koşul ve uygulamaları ifade eder. Demir vd. (2021) çalı̧̧masında hijyenin otel işletmelerinin sağlkklı ve güvenli ortam oluşturması için önemli olduğunun altını çizmiştir. Günümüzde Covid-19 salgını nedeniyle müşteriler için otelin hijyen bakımından güvenilir olması en çok dikkat edecekleri hususlardandır (Yu vd., 2018; Roy vd., 2019).

Otel ücreti: Fiyat, bir odanın konaklama ücretini ifade eder. Sınırlı sayıda müşteri ağırlayacak olması ve pandemi nedeniyle girdi maliyetlerinin artması oda fiyatlarını etkilemektedir (Yu vd., 2018; Roy vd., 2019; Sürücü vd., 2020). Otel ücreti ve performans kriteri "Etstur ve Trivago" resmi web sitesinden alınan yorumlar ve puanlara göre değerlendirmeye alınmıştır. Otelin oda özellikleri otel ücreti konusunda en önemli etkenlerdendir. Odalarda günlük çarşaf değişimi yapılırken, dezenfekte işlemi, tek kullanımlık kişisel bakım ürünleri bulunmaktadır.

Coğrafi Lokasyon: Otelin konumu merkezi yerlere yakın olması müşteriler için en önemli hususlardan bir tanesidir (Aksoy ve Ozbuk, 2017; Yu vd., 2018; Kwok ve Lau, 2019; Roy vd., 2019; Sürücü vd., 2020). Müşteriler için havaalanına yakınlık, tarihi yerler ve koylara yakın olması otel seçimi karar verme sürecinde büyük etki oluşturmaktadır.

Otelin Fiziksel Özellikleri: Otelin sahip olduğu tüm fiziksel özellikleri ifade eder (Yu vd., 2018; Roy vd., 2019). Fiziksel özellikleri de kapsayan bazı önlemler sıralanmıştır. Otellerde toplu alan kullanımının en önemli en kalabalık olduğu yerler sahiller ve havuzlar olarak belirlenmiştir. Havuzlar ve sahillerde müşterilerin kendi havluları veya tek kullanımlık havlu kullanmaları gereklidir. Lobide maske kullanım zorunluluğu, temassız ödeme ve termal ateş ölçer ile kontroller yapılmakta ve gerekli önlemler alınmaktadır. Restoranlarda açık büfe önlerinde bariyer çekilerek sosyal mesafeye uydukları belirlenmiştir. Açık büfelerde personel bulundurarak kalabalığı engellenmek hedeflenmiştir. Restoranlarda kullanılan çatal, kaşık, tabak, bardak vs. gibi araç gereçler her kullanımdan sonra dezenfeksiyon işlemi gerçekleştirerek yıkandığı öngörülmüştür.

Müșteri İlişkileri: Otellerin resmi web sitelerinde yayımladıkları pandemi koşulları hakkında alınan önlemleri ve müşteri ilişkilerini kapsayan kriterdir. Müşterilerin otele girişlerinde otelin aldığı pandemi kuralları hakkında bilgilendirilmesi, müşterilerin gerekli testlere tabi tutulması ve önlemlere uymama koşulunda yapılacakları kapsamaktadır (Kıvilcım; 2020).

Personel: Otellerin resmi web sitelerinden edinilen bilgilere göre personelin maske kullanımı, eldiven kullanımına dikkat ettikleri öngörülmüştür. Kültür Turizm Bakanlığı ve Sağlık Bakanlığının açıklamasında yer alan bilgiye göre Turizm sektöründe çalışan kişiler aşılanmıştır (Kıvılcım; 2020).

Tavsiye Edilme: Otellerin tavsiye edilme puanı ve yorumları Etstur ve Trivago internet siteleri üzerinden alınmıştır. Daha önce 
konaklama yapan müşterilerin olumlu ve olumsuz yorumları müşterilerin karar verme süreçlerini etkilediği düşünülmektedir. Olumlu sonuçlar yeni gelecek müşteriler için tavsiye niteliği sağlamaktadır (Yu vd., 2018; Kwok ve Lau, 2019; Roy vd., 2019 Sürücü vd., 2020). Müşterilerin bu yorumlarda en çok dikkatini çeken hususlar otellerin pandemi koşullarında aldıkları önlemlere uyup uymadıklarıdır.

\subsection{Otel Seçiminde Kullanılan ÇKKV Teknikleri}

Literatürde farklı alanlarda uygulanan çeşitli ÇKKV yöntemleri bulunmaktadır (Bulak vd., 2021; Kekilli vd., 2021). ÇKKV, birden fazla disiplinin bir arada var olmasına ve karar vericilerin farklı boyutlarda değerlendirilmesine, ve en olası kararın bulunmasına olanak sağlar (Gavcar ve Kara, 2020; Yiğit vd., 2021). Karar verme yöntemleri arasında, Analitik Hiyerarşi Süreci (AHP), Elemination and Choice Translating Reality English (ELECTRE), TOPSIS, Preference siralama organizasyon metodu zenginleştirme değerlendirmesi (PROMETHEE) ve VlseKriterijumska Optimizacija IKompromisno Resenje (VIKOR) literatürde en sık kullanılan yöntemlerdir (Güleryüz, 2020). Çalışmada ele alınan TOPSIS yöntemi, farklı kriterlere bağlı olarak değerlendirilen alternatifler arasından seçim yapılması ve alternatiflerin siralanmasına imkan sağlayan kullanışlı bir tekniktir.

Literatürde pandemi koşulları ve otel seçimi ile ilgili birçok makale bulunmaktadır. Chen vd. (2012) çalışmalarında iki aşamalı bir yaklaşım uygulayarak otel değerlendirmesi yapmışlardır. Birinci aşamada Delphi tekniği kullanılmış sonrasında AHP ve Bulanık AHP yöntemi kullanılarak değerlendirmeler sunulmuştur. Kundakçı vd. (2015) AHP tekniğini kullanarak otel kuruluş yeri seçimi üzerine çalışmışlardır. Sarıçalı ve Kundakçı (2016) tatil için otel alternatiflerini değerlendirmek amacıyla AHP ve COPRAS yöntemlerini kullanarak en iyi alternatifi seçmişlerdir. Zaman vd. (2016) AHP yöntemi kullanılarak Paris'te 250 turistte anket yapılmıştır. $\mathrm{Bu}$ anket sonucunda AHP ile otel seçimi uygulanmasının kolaylaştırılması hedeflenmiştir. Ecemiş ve Yaykaşlı (2018) yapmış oldukları çalışmada ziyaretçilerin kriterlere verdikleri önem derecesi TOPSİS yöntemi ile bulunmuş ve Antalya bölgesinde yer alan 140 otel değerlendirilmiştir. Öztel, Karakaş ve Aslan (2018) İstanbul'da faaliyet gösteren beş yıldızlı oteller arasından bulanık TOPSIS tekniğiyle 10 kriter kullanarak otel seçimi yapmışlardır. Çaylak (2019) Antalya'da bulunan 11 farklı otelin değerlendirilmesini TOPSİS yöntemi kullanarak en iyi sonucu hesaplamıştır. Kwok ve Lau (2019) yapmış oldukları çalışmada ziyaretçilerin otel seçimleri için Belirsiz Küme TOPSIS tekniğini uygulamışlardır. Sürücü vd. (2020) Afyonkarahisar'da bulunan termal otellerin seçimi Bulanık TOPSİS yöntemini kullanarak otel seçiminin nasıl yapılacağı analiz edilmiştir. Bahar ve İlal (2020), yaptıkları çalışmada daha önce yaşanan krizlerin turizm etkisi ve Covid-19 salgınının turizm etkisini incelemişlerdir. Acar (2020), Dünya Turizm Örgütü'nün (WTO) Covid-19 salgını kapsamında hazırladığı raporda, ülkelerin ekonomik açıdan aldıkları zarar turizm sektörünü doğrudan etkilemiştir. Yapılan çalışmada bu etkiler incelenerek çıkarımlar yapılmıştır. Chang vd. (2020), Covid-19 salgınında turizmden kaynaklanan seyahat, konaklama ve misafirperverlik olumsuz derecede etkilenmiştir. Bu makalede Covid-19 salgını sonrası turizm ve seyahat için öngörüde bulunulmuştur. Kıvılcım (2020), Covid-19 salgınında turizm sektörü her açıdan olumsuz etkilenmiş ve buna karşın değişim göstermiştir. Çalışmada, Covid-19 sonrası oluşacak olası yenilik ve değişimlerden bahsedilmiştir. Ulucan (2020) yapmış olduğu çalışmada otel yeri seçimi için bulanık TOPSIS yaklaşımı kullanmışlardır. Arancıoğlu vd. (2021) yılında yapılan araştırmada Covıd-19 salgını sırasında üniversite öğrencilerinin stres ve beslenme durumları değerlendirilmiştir. Demir vd. (2021) pandemi koşulları dikkate alınarak müşterilerin otel seçimlerini nasıl etkilediği ve alınan önlemleri sunmuştur. Demirbilek (2021) yapılan araştırmada Okul/İş yeri kapatılmasının Covıd-19 kaynakları vaka sayılarına etkisi göz önünde bulundurularak altı farklı ülkenin Covid-19 istatistikleri alınarak hesaplanmıştır. Bozkurt (2021) yapılan araştırmada Covid-19 salgını taşıyan hastaların x-ray tomografi cihazları kullanılarak daha hızlı tespit edildiği vurgulanmıştır.

Yukarıdaki bilgilere göre, araştırmacılar çeşitli uygulama alanlarında ve farklı tekniklerle çalışmaktadırlar. Yayınlarda yazarlar pandemide seçim problemini modellemiş, gerçek uygulamada ise çalışmalar daha sınırlı kalmıştır. Dolayısıyla literatürde pandemi ele alınarak gerçek uygulamalarda otel seçiminde halen boşluk tamamlanmamıştır. Ayrıca otel seçimiyle ilgili çalışma olmasına rağmen, uzman görüşü ve web sitelerindeki bilgileri ve değerlendirmeleri pandemi süresince baz alan çalışmaya yazında rastlanmamıştır. Böylelikle çalışmanın literatürdeki boşluğu doldurması planlanmaktadır.

\section{Metodoloji}

$\mathrm{Bu}$ bölüm, çalışmada kullanılan metodolojiyi kısaca sunmaktadır.

\subsection{TOPSIS}

Çok kriterli karar verme yöntemlerinden biri olan TOPSIS yılında Hwang ve Yoon tarafindan çözüm alternatifinin, pozitif ideal çözüm noktasına en kısa mesafe ve negatif ideal çözüm noktasına en uzak mesafede olduğu varsayımına göre oluşturmuşlardır (Hwang ve Yoon, 1981). Bu yöntemde ' $k$ ' sayıda altenatif ' $n$ ' sayıda kriter belirlenerek, maksimum ve minimum ideal değerler karşılaştırılarak en uygun çözüme ulaşılması hedeflenmiştir.

$A=\left[\begin{array}{lll}a_{11} & a_{21} & a_{31} \\ a_{21} & a_{22} & a_{32} \\ a_{31} & a_{23} & a_{33}\end{array}\right]$

Adım 1: Başlangıç matrisi oluşturulmuştur (1).

$r_{i j}=\frac{\mathrm{a}_{\mathrm{ij}}}{\sqrt{\sum_{k=1}^{n} a_{k_{j}}^{2}}}$

$\left(r_{i j} ; i,: 1,2, \ldots, n ; k r i t e r\right.$ Sayls $\iota j: 1,2, \ldots, k$; alternatif saylsi)

Adım 2: Karar matrisi oluşturulduktan sonra (2) ile normalizasyon işlemi gerçekleştirilir.

Adım 3: Ağırlıklandırılmış normalize matris elde edildikten sonra (3), (4) ile ideal olan ve olmayan çözüm değerleri elde edilir.

$$
\begin{aligned}
& A^{*}=\left\{\left(\max _{i} v_{i j} \mid j \in J\right), \quad\left\{\left(\min _{i} v_{i j} \mid j \in J^{\prime}\right)\right\}\right. \\
& A^{-}=\left\{\left(\min _{i} v_{i j} \mid j \in J\right), \quad\left\{\left(\max _{i} v_{i j} \mid j \in J^{\prime}\right)\right\}\right.
\end{aligned}
$$


Adım 4: ideal olan ve ideal olmayan noktalar arasındaki uzaklık (5), (6) ile hesaplanir.

$$
\begin{aligned}
& S_{j}^{*}=\sqrt{\sum_{j=1}^{n}\left(v_{i j}-v_{j}^{*}\right)^{2}} \\
& S_{j}^{-}=\sqrt{\sum_{j=1}^{n}\left(v_{i j}-v_{j}^{-}\right)^{2}}
\end{aligned}
$$

Adım 5: Her bir karar noktası ideal çözüm olan göreli yakınlığı hesaplamasında (7) kullanılır ve en uygun alternatif seçilir.

$C_{i}^{*}=\frac{s_{j}^{-}}{s_{i}^{-}+s_{i}^{*}} \quad 0 \leq C_{i}^{*} \leq 1$

\section{Uygulama}

Adım 1: Karar vericilerin belirlenmesi ve değerlendirme modelinin oluşturulması. Yapılan değerlendirmelerde elde edilen kriterler ve uzmanların belirledikleri ağırlıklar Tablo 1'de verilmiştir. HJ: Hijyen, OÜ: Otel ücreti, CL:Coğrafi lokasyon, OFÖ: Otelin fiziksel özellikleri, Mİ: Müşteri ilişkileri, PE: Personel ve TE: Tavsiye edilme kriterlerini göstermektedir. Alternatifler Rixos Beldibi (O1), Susesi Luxury Resort (O2), Akka Antedon Hotel (O3), Voyage Belek Golf \& Spa (O4), Kaya
Palazzo Golf Resort (O5), Selectum Luxury Resort (O6), Regnum Carya Belek (O7) olarak belirlenmiştir.

Adım 2: Karar matrisinin (O) oluşturulması. Otelin kriterleri belirlenerek bu kriter puanları "Trivago" ve "Etstur"dan alınmıştır. Tablo 1'de kriter ağırlıkları ve Tablo 2'de karar matrisi gösterilmiştir.

Adım 3: Karar matrisi oluşturulduktan sonra normalleştirilmiş karar matrisini oluşturmak için (2) numaralı formül kullanılmıştır. Normalleştirilmiş karar matrisi Tablo 3 'te verilmiştir.

Adım 4: Ağırlıklı karar matrisinin oluşturulması. Kriter ağırlık değeri ile Tablo 2'de oluşturulan karar matrisinin her bir sütundaki değerleri çarpılarak ağırlıklı normalleştirilmiş karar matrisi elde edilir. Tablo 4'te gösterilmiştir.

Adım 5: İdeal $\boldsymbol{A}^{+}$ve Negatif ideal $\left(\boldsymbol{A}^{-}\right)$çözümlerinin oluşturulması. İdeal çözüm ağırlıkları en iyi performans sonuçlarını gösterirken negatif ideal çözüm en kötü sonuçları gösterir. Tablo 5' te gösterilmiştir.

Adım 6: İdeal çözümden uzaklığı ideal ayrım( $\left.\boldsymbol{x}^{+}\right)$ve negatif ideal çözüme uzaklığı ideal ayrımı $\left(\boldsymbol{x}^{-}\right) 5$ ve 6 numaralı denklem kullanılarak Tablo 6'da gösterilmiştir.

Adım 7: Bu adımda ideal çözüme yakınlık hesaplanmıştır.

Adım 8: En uygun otellerin sıralaması belirlenerek Tablo 7'de gösterilmiştir.

Tablo 1: Kriter Ağırlıkları

\begin{tabular}{lccccccc} 
Kriter & HJ & OÜ & CL & OFÖ & MI & PE & TE \\
\hline Ăğırlık & 0.20 & 0.12 & 0.15 & 0.15 & 0.10 & 0.15 & 0.13
\end{tabular}

Tablo 2: Karar Matrisi

\begin{tabular}{lccccccc}
\hline Alternatifler & HJ & OÜ & CL & OÖF & Mi் & PE & TE \\
\hline Rixos Beldibi (O1) & 9.2 & 8.3 & 9.8 & 8.6 & 8.2 & 8.4 & 8.6 \\
Susesi Luxury Resort (O2) & 9.1 & 8.6 & 8.7 & 8.6 & 9.0 & 8.7 & 8.9 \\
Akka Antedon Hotel(O3) & 8.8 & 8.7 & 9.7 & 8.2 & 8.9 & 8.5 & 9.3 \\
Voyage Belek Golf \& Spa (O4) & 9.3 & 8.9 & 9.7 & 8.2 & 9.6 & 8.9 & 9.6 \\
Kaya Palazzo Golf Resort (O5) & 8.7 & 9.0 & 9.9 & 8.5 & 9.6 & 8.6 & 9.3 \\
Selectum Luxury Resort (O6) & 9.0 & 8.1 & 9.7 & 8.5 & 9.5 & 8.8 & 8.7 \\
Regnum Carya Belek (O7) & 9.5 & 8.9 & 8.2 & 8.7 & 9.4 & 9.3 & 9.0 \\
\hline
\end{tabular}

Tablo 3: Normalleştirilmiş Karar Matrisi

\begin{tabular}{llllllll}
\hline & HJ & OÜ & CL & OFÖ & MI & PE & TE \\
\hline O1 & 0,382 & 0,362 & 0,393 & 0,372 & 0,337 & 0,362 & 0,358 \\
O2 & 0,378 & 0,375 & 0,349 & 0,385 & 0,370 & 0,375 & 0,370 \\
O3 & 0,365 & 0,380 & 0,389 & 0,367 & 0,366 & 0,367 & 0,387 \\
O4 & 0,386 & 0,388 & 0,388 & 0,367 & 0,395 & 0,38 & 0,399 \\
O5 & 0,36 & 0,393 & 0,397 & 0,381 & 0,395 & 0,371 & 0,387 \\
O6 & 0,374 & 0,353 & 0,389 & 0,381 & 0,390 & 0,380 & 0,366 \\
O7 & 0,395 & 0,388 & 0,329 & 0,390 & 0,386 & 0,401 & 0,374 \\
\hline
\end{tabular}


European Journal of Science and Technology

Tablo 4: Ağırlıklı Normalleştirilmiş Karar Matrisi

\begin{tabular}{llllllll}
\hline Max & 0,079 & 0,047 & 0,059 & 0,058 & 0,039 & 0,060 & 0,051 \\
Min & 0,072 & 0,042 & 0,049 & 0,055 & 0,033 & 0,05 & 0,046 \\
\hline
\end{tabular}

Tablo 5: Negatif ve Pozitif İdeal Çözümler

\begin{tabular}{llllllll}
\hline & HJ & OÜ & CL & OFÖ & MI & PE & TE \\
\hline O1 & 0,076 & 0,043 & 0,059 & 0,05 & 0,033 & 0,054 & 0,046 \\
O2 & 0,075 & 0,045 & 0,052 & 0,057 & 0,037 & 0,056 & 0,048 \\
O3 & 0,073 & 0,045 & 0,058 & 0,055 & 0,036 & 0,055 & 0,050 \\
O4 & 0,077 & 0,046 & 0,058 & 0,055 & 0,039 & 0,057 & 0,051 \\
O5 & 0,072 & 0,047 & 0,059 & 0,057 & 0,039 & 0,055 & 0,050 \\
O6 & 0,074 & 0,042 & 0,058 & 0,057 & 0,039 & 0,057 & 0,047 \\
O7 & 0,079 & 0,046 & 0,049 & 0,058 & 0,038 & 0,060 & 0,048 \\
\hline
\end{tabular}

Tablo 6: Ayrım Ölçümleri

\begin{tabular}{ccc}
\hline $\begin{array}{c}\text { Ayrım } \\
\text { Ölçümleri }\end{array}$ & $\boldsymbol{X}^{+}$ & $\boldsymbol{X}^{-}$ \\
\hline O1 & 0,105 & 0,102 \\
O2 & 0,100 & 0,084 \\
O3 & 0,096 & 0,103 \\
O4 & 0,068 & 0,118 \\
O5 & 0,091 & 0,115 \\
O6 & 0,092 & 0,106 \\
O7 & 0,103 & 0,108 \\
\hline
\end{tabular}

Tablo 7: Otel Siralaması

\begin{tabular}{lll}
\hline & Otel Adı & Sonuç \\
\hline 1 & Voyage Belek Golf\&Spa & $\mathbf{0 , 6 3 2}$ \\
2 & Kaya Palazzo Golf Resort & $\mathbf{0 , 5 5 9}$ \\
3 & Selectum Luxury Resort & $\mathbf{0 , 5 3 5}$ \\
4 & Akka Antedon Hotel & 0,517 \\
5 & Regnum Carya Belek & 0.509 \\
6 & Rixos Beldibi & 0,493 \\
7 & Susesi Luxury Resort & 0,456 \\
\hline
\end{tabular}

\section{Sonuç}

Günümüzde çevrimiçi otel seçiminde kullanıcıların otellerin puanları ve diğer müşteri yorumlarından etkilenerek seçim yaptı̆̆ öngörülmüştür. Bunun yanı sıra bulunduğumuz pandemi döneminde müşteriler için güvenli turizm sertifikası gibi yeni kriterler ön plana çıkmıştır. Türkiye'deki oteller Kültür ve Turizm Bakanlığı ve Sağlık Bakanlığı'nın yayımladığı ortak genelge ile pandemi koşullarını uygulamak koşuluyla bu sertifikayı almayı hak etmişlerdir.

Çalışmada Etstur ve Trivago sitelerinde yer alan Hijyen, Otel Ücreti, Coğrafi Lokasyon, Otelin Fiziksel Özellikleri, Müşteri İlişkileri, Personel ve Tavsiye Edilme değerlendirilme kriterleri olarak ele alınmıştır. Web sitelerinde bulunan Müşteri ilişkileri kriteri otelin Genel Puanı ile değerlendirilmiş, Otelin Fiziksel özellikleri ise Otelin Bina puanı dikkate alınarak değerlendirilmiştir. Coğrafi Lokasyon otelin konumu ve önemli yerlere (Ulaşım, Tarihi yerler, Merkezi yerleşim) yakınlık baz alınarak bu değerlendirme yapılmıştır.

Araştırma kapsamında ele alınan ve Antalya'da bulunan 7 otelin kriterleri "Trivago, Etstur ve uzman görüşlerinden" yararlanarak değerlendirilmiş ve en uygun otel TOPSIS yöntemiyle seçilmiştir.Yapılan değerlendirmeye göre otel siralamasında Voyage Belek Golf \& Spa en uygun otel olarak belirlenmiş sonrasında Kaya Palazzo Golf Resort ve Selectum Luxury Resort sırasıyla analizde yerini almıştır.

Çalışmada görüşlerini sunan uzmanlara göre en önemli kriterin "hijyen" olduğu görülmüştür. Özellikle tüm dünyada etkisini gösteren Covid-19 pandemi sürecinde insanların hijyen konusundaki farkındalığının arttı̆̆ 1 ve otel seçiminde önem verdiği kriterlerin başında geldiği düşünülmektedir. Literatür incelendiğinde seçilen kriterlerin önem düzeylerinde farkl1lıklar olduğu görülmüsşür. Sürücü ve arkadaşları (2020) "müşteri yorumları" kriterinin araştırmalarında en önemli kriterler olarak belirlenmişlerdir. $\mathrm{Bu}$ bağlamda kriterlerin önem derecesinin 
seçilen uzmanlara veya karar vericilere göre değişebileceği söylenebilir.

Literatürde yayınlanan çalışmalardan örneğin Çaylak (2019) TOPSIS yöntemiyle otel seçimini ele almış ancak farklı kriterler dikkate alarak değerlendirme yapmıştır. Diğer çalışmalardan ayrılan nokta, bu çalışmada literatürde ilk kez pandemi koşulları da dikkate alınarak gerçek bir uygulmayla en uygun otel seçimi yapılmıştır.

Araştırma sürecinde karşılaşılan bazı sınırlamalar bulunmaktadır. Nihai sonuçların karar vericinin görüşlerini yansıttığ 1 ve ideal durumların karar vericiye bağlı olduğu durumlarda belirlenen sonuçlarda oluşabilecek sapmalar çalışmada dikkate alınmamıştır. Bu durumun etkisini ortadan kaldırabilmek ve gelecek çalışmalar için ya daha fazla uzmanın görüşünden faydalanmak gerekmekte ya da diğer ÇKKV yöntemlerinden küresel bulanık TOPSIS yöntemi ile karşılaştırmalı analiz yapılması hedeflenmektedir.

\section{Teșekkür}

Otellerin resmi web siteleri, EtsTur ve Trivago'nun paylaştıkları otel bilgileri için teşekkürlerimizi sunarız. Ayrıca, Rixos Otel Beldibi'nde görevli uzman sayın Esra Karabulut'a verdiği değerli bilgiler için teşekkür ederiz.

\section{Kaynakça}

Acar, Y . (2020). Yeni Koronavirüs (COVID-19) Salgını ve Turizm Faaliyetlerine Etkisi. Güncel Turizm Araştırmaları Dergisi, 4 (1) , 7-21.

Aksoy, S. ve Ozbuk, M. Y. (2017). Multiple criteria decision making in hotel location: Does it relate to postpurchase consumer evaluations. Tourism Management Perspectives, $22,73-81$

Bahar, O, Çelik İlal, N. (2020). Coronavirüsün (Covid-19) turizm sektörü üzerindeki ekonomik etkileri. International Journal of Social Sciences and Education Research, 6 (1) , 125-139.

Bozkurt, F. (2021). Derin Öğrenme Tekniklerini Kullanarak Akciğer X-Ray Görüntülerinden COVID-19 Tespiti. Avrupa Bilim ve Teknoloji Dergisi, Ejosat Özel Say1 2021 (ARACONF), 149-156.

Bulak, M. E., Kozanoğu, O., Aydoğduoğlu,Ş. N., Göçer, F., ve Algül, R. (2021). E-Ticaret sitelerinin kullanılabilirliğinin AHP ve TOPSIS yöntemleriyle karşılaştırılması. European Journal of Science and Technology, (26), 493-509.

Chang, C.-L., McAleer, M. ve Ramos, V. (2020). COVID-19 Sonrası Sürdürülebilir Turizm Sözleşmesi, Sürdürülebilirlik, 12 (9), 3671.

Chen, YC., Yu, TH. ve Tsui, PL. (2014). Uluslararası otel spa atmosferi değerlendirme modeli oluşturmak için bulanık bir AHP yaklaşımı. Quality \& Quantity, 48, 645-657.

Çaylak, M. (2019). Topsis yöntemi ile en uygun otel seçimi. Oğuzhan Sosyal Bilimler Dergisi, 1 (2), 65-76.

Demir, M., Demir, Ş., Ergen, F. ve Dalgıç, A. (2021). Covid-19 sürecinde tüketicilerin otel seçimini etkileyen faktörler. International Journal of Social Sciences and Education Research, 7 (1), 82-94.

Demirbilek, M. (2021). The effect of school/workplace closures on COVID-19 related incidents. Avrupa Bilim ve Teknoloji Dergisi, (23), 62-69 .
Ecemiş, O., Yaykaşlı, M. (2018). Topsis yöntemiyle otel seçimine yönelik bir karar destek sistemi. Akademik Sosyal Araştırmalar Dergisi, 74, 326-337.

Gavcar, E., Kara, N. (2020). Elektrikli Otomobil Seçiminde Entropi ve TOPSIS Yöntemlerinin Uygulanması. İş ve Insan Dergisi, 7 (2), 351-359.

Güleryüz, S. (2020). Evaluation of Product Development Partner Selection Process Using Multi Criteria Decision Making Approach. Avrupa Bilim ve Teknoloji Dergisi, (Special Issue), 307-311.

Hwang, C.L. ve Yoon, K.P. (1981). Multiple attribute decisionmaking: Methods and application, Springer, New York.

Kekilli, E., Cebeci, U. ve Silay, L. (2021). Selection of VFQ Consultant by Using Integrated Fuzzy AHP and Fuzzy TOPSIS. European Journal of Science and Technology, (24), 262-267.Kwok, P. K. ve Lau, H. Y. (2019). Hotel selection using a modified TOPSIS-based decision support algorithm. Decision Support Systems, 120, 95-105.

Kundakcı, N., Adalı Aytaç, E., ve Tuş Işı1k, A. (2015). Tourist hotel location selection with analytic hierarchy process. Journal of Life Economics, 5, 47-58.

Özay Arancıoğlu, İ. , Yılmaz, H. K. , Ergüden, B., Derya İpek, K. Yıldırım, Ç. ve Bora, S. (2021). Evaluation of Stress and Nutrition Status of University Students During the Covid-19 Outbreak, Avrupa Bilim ve Teknoloji Dergisi, (25), 707-714 .

Öztel, A., Karakaş, A. ve Aslan, A. (2018). Green star hotel selection with fuzzy TOPSIS method: Case of Istanbul. Recent Researches on Social Sciences, 473.

Sarıçalı, G., Kundakçı, N. (2016), AHP ve Copras yöntemleri ile otel alternatiflerinin değerlendirilmesi. International Review of Economics and Management (IREM), 4 (1), 45-66.

Sürücü, Ç , Yavuz, H , Öztel, A . (2020). Bulanık TOPSIS Yöntemi ile Termal Otel Seçimi: Afyonkarahisar Örneği . Bartın Üniversitesi İktisadi ve İdari Bilimler Fakültesi Dergisi, 11 (21) , 22-38.

Yiğit, M.E. ve Akpınar M.E. (2021). Rüzgar türbin kulesi alternatiflerinin çok kriterli karar verme yöntemleri ile değerlendirilmesi. Avrupa Bilim ve Teknoloji Dergisi, (23), 386-393.

Ulucan, E. (2020). Otel yeri seçimi: Faktörlere göre bulanık TOPSIS ile konum belirleme. European Journal of Tourism, Hospitality and Recreation, 10(3), 213-228.

Yu, S. M., Wang, J., Wang, J. Q. ve Li, L. (2018). A multi-criteria decision-making model for hotel selection with linguistic distribution assessments, Applied Soft Computing, 67, 741755.

Zaman, M., Botti, L. ve Thanh, T. (2016). Otel seçiminde kriterlerin ağırlığı: TripAdvisor kriterlerine dayalı ampirik bir örnek. European Journal of Tourism Research , 13, 132 -138. 